\title{
Merlín: formación de la leyenda
}

\author{
Rosalba LENDO \\ Universidad Nacional Autónoma de México
}

Si bien el nombre de Merlín (en latín Merlinnus y en galés Myrddin) aparece por primera vez en una obra de Geoffrey de Monmouth, las Prophetiae Merlini (1135), el personaje parece ser anterior. Sin embargo, los estudiosos coinciden en afirmar que es a partir de Geoffrey cuando da inicio el desarrollo de la leyenda de Merlín y Arturo, gracias a la obra antes mencionada, pero sobre todo a otra creación del clérigo galés, la Historia Regum Britanniae (1138), que tuvo durante la Edad Media un éxito inmediato y una gran difusión, despertando así un profundo interés por el rey Arturo y sus aventuras, que se convertirán en la base de lo que se conoce como novela artúrica.

Es verdad que Geoffrey sentó los fundamentos necesarios para la construcción y divulgación de la leyenda artúrica, pero no fue él el primero en hablar de Arturo o de Merlín. Es por ello que, antes de abordar la obra de este escritor, nos parece conveniente mencionar algunos textos anteriores donde figuran ya dichos personajes. Respecto a Arturo se conocen escritos mucho más antiguos que atestiguan la existencia de una leyenda aún repleta de elementos mitológicos celtas. Entre éstos, en su gran mayoría de origen galés, cabe señalar un poema del siglo VII, Goddodin, que relata la derrota de los bretones durante una batalla contra los anglos, y donde Arturo es recordado como un famoso guerrero ya muerto. Existen dos obras más que es importante mencionar: Kulhwch y Olwen y El sueño de Rhonabwy. El primero es considerado por la crítica como uno de los más antiguos textos artúricos; en él se mezclan leyendas irlandesas, recibidas por los bretones, con cuentos locales. Los personajes son magos, dioses, guerreros y caballeros del rey Arturo, y la trama es la búsqueda de objetos maravillosos necesarios para que Kulhwch, primo de Arturo, obtenga la mano de su amada Olwen. El sueño de Rhonabwy es un relato que evoca la corte del rey Arturo, y en el que aparecen éste y otros personajes más, que cobrarán después gran importancia dentro de la novela artúrica: Yvain, Urien, su padre, y Keu, el 
senescal del rey. Estas narraciones forman parte de los escritos galeses conservados en el Libro Negro de Camarthen (siglo XIII), en el Libro Blanco de Ryderch (siglo XIV) y en el Libro Rojo de Hergest (siglo XV), obras que recogen diversos relatos de tradición oral muy antigua. Algunos de ellos fueron recopilados y publicados en 1838 por Lady Guest bajo el título Mabinogion.

Respecto de los orígenes de Merlín, en los Mabinogion sólo encontramos ciertos textos donde aparecen personajes similares. Podemos mencionar, por ejemplo, el relato titulado Math, hijo de Mathonwy, donde interviene Math, un poderoso mago, y Gwyddon, un encantador que posee muchas de las características de nuestro personaje. Posiblemente la primera pista que se tiene de Merlín está en una serie de poemas que figuran en el Libro Negro de Camarthen y en el Libro Rojo de Hergest. Dichos poemas, todos apócrifos, se le atribuyen a un bardo llamado Myrddin, que parece haber vivido durante el siglo vI y que se relaciona íntimamente con Merlín, al menos con el personaje de la Vita Merlini, de Geoffrey de Monmouth. En ellos el bardo describe su vida solitaria en el bosque, donde buscó refugio tras el gran dolor de la derrota en una batalla. Posiblemente se trata del mismo combate al que se refieren los Annales Cambriae (siglo X), donde se relatan algunos sucesos acontecidos en el siglo VI, como la batalla de Ardderyd (573) llevada a cabo entre dos jefes bretones, Gwendoleu y Peredeur. Ante el terrible espectáculo de esta guerra en la que participa, Myrddin enloquece y huye al bosque. Ésta es la historia retomada por Geoffrey al inicio de su Vita Merlini. Los Annales Cambriae no sólo señalan la existencia de un bardo muy semejante a Merlín, hablan también de Arturo, jefe guerrero de alguna tribu de bretones del norte, y describen el combate de Badon (516), en el que Arturo resulta vencedor, y el de Camlann (537), en el que cayeron él y Merdaut (Mordred en la novela artúrica).

Otro texto en el que encontramos a un personaje similar a Merlín, sobre todo al de la Vita Merlini, es la Vida de San Kentigern, escrita en el siglo XII por el monje Jocelyn. Kentigern fue un evangelizador que fundó el monasterio de San Asaph, en Gales del Norte, en el siglo VI. Cabe señalar aquí que unos siglos más tarde, en 1151, Geoffrey será nombrado obispo de este monasterio, y que posiblemente conoció la historia. La Vida de San Kentigern menciona a un hombre llamado Lailoken que vivía solo en el bosque en el sur de Escocia y se dedicaba a profetizar. Jean Markale, en su estudio sobre Merlín, ${ }^{1}$ plantea que este hombre, contemporáneo de Kentigern, es el mis-

' Jean Markale, Merlin l'enchanteur ou l'éternelle quête magique, pp. 47-49. 
mo bardo de los Annales Cambriae. Se trata, según el crítico, de alguien que vivió a mediados del siglo $\mathrm{VI}$.

Como lo hemos señalado, Geoffrey de Monmouth escribió tres obras fundamentales para la elaboración de la leyenda artúrica. La más importante es sin duda alguna la Historia Regum Britanniae, que narra la historia bretona, desde el reinado de Bruto, bisnieto de Eneas (siglo XII a. C.), hasta el de Cadvaladro (siglo vIl d. C.). Al incio de su texto el autor aclara que éste no es más que la traducción al latín de un manuscrito en lengua bretona. No se sabe si verdaderamente existió dicha obra, lo que sí se puede decir es que el clérigo galés se inspiró en las crónicas de Guillermo de Malmesbury, en leyendas y relatos de origen celta, en autores latinos como Cicerón, Virgilio y Lucano, y, sobre todo, en tres obras que vale la pena destacar: De exidio et conquestu Britanniae, atribuida a Gildas y realizada hacia 547, donde se relata la emigración bretona hacia Armórica (Bretaña francesa), que tuvo lugar tras la caída del imperio romano, cuando la isla británica fue invadida por anglos, sajones y pictos. Las otras dos obras son la Historia ecclesiastica gentis Anglorum de Beda, benedictino que vivió entre 673 y 735, y la Historia Britonum del sacerdote galés Nenio, cuya vida se desarrolló durante el siglo IX. Parece ser que Nenio es solamente el interpolador de este texto que es en realidad mucho más antiguo. ${ }^{2}$ Arturo es presentado aquí como un jefe guerrero que obtiene el triunfo en un combate contra los sajones. El héroe se convierte en un gran libertador a quien se le atribuyen otras victorias más, muchas de ellas localizadas en la actual frontera de Escocia y el bosque de Celydon. También aparece ya en esta obra el famoso episodio del rey Vortigern, donde interviene el niño dotado de poderes maravillosos, que será más tarde el Merlín de la Historia Regum Britanniae.

Al redactar su Historia, Geoffrey cumplía con una necesidad de la época, escribir la historia nacional. Si no tenía los elementos suficientes, o si deseaba glorificarla, había que inventar; lo que contaba era el deseo de magnificar y dar título de nobleza al pueblo bretón. Es por esto que, años después, la nueva política cultural anglo-angevina recibirá muy bien su obra e impulsará el desarrollo y la divulgación de la leyenda artúrica. Los Plantagenêt, opuestos a la dinastía de los Capeto, cuyo héroe representativo era Carlomagno, tenian que buscar un equivalente para la Bretaña insular, y quién mejor que Arturo, que se cubrirá de gloria en la Historia Regum

${ }^{2}$ En La légende arthurienne et le Graal, Jean Marx, siguiendo la tesis de Ferdinand Lot, plantea que la Historia Britonum tuvo como base un texto del año 700 aproximadamente. Según el critico, Nenio, quien escribe a principios del siglo IX, es el primer interpolador del texto primitivo. 
Britanniae. Y aunque de él ya se había hablado antes, Geoffrey lo transforma, de un personaje más o menos preciso en los relatos de tradición oral y en el folclor bretón, en un gran rey, en un verdadero conquistador que llegó a someter a muchos pueblos. El clérigo galés dedica una parte de su obra al relato de las aventuras y proezas de Arturo. Y fue probablemente el primero en introducir al personaje de Merlín en este universo. Inspirándose en la Historia Britonum de Nenio, Geoffrey presenta en su relato al personaje del niño sin padre, Merlín, autor de una serie de enigmáticas profecías relativas a la gloria y decadencia del pueblo bretón. El profeta es presentado aquí como el hijo de un demonio íncubo y una princesa demecia. Dotado de poderes extraordinarios, Merlín se convierte en el consejero y protector de los reyes bretones, Uter y Pendragón. Su participación en la consolidación de la paz en el reino y en la preparación del advenimiento de Arturo será determinante. Gracias a la intervención del mago se llevará a cabo la unión entre Uter e Igerna, esposa del duque de Cornubia, en la que será concebido Arturo, el futuro rey de Bretaña. Merlín desaparece de escena cuando Arturo nace.

Las Prophetiae Merlini, escritas por el mismo autor, son una serie de profecías de Merlín sobre el pueblo bretón. En un principio constituían un texto independiente pero más tarde fueron incluidas en la Historia.

La Vita Merlini (1148-1150) parece haber sido el último texto de Geoffrey, pues no se conoce ningún otro posterior y el clérigo muere unos años después, en 1155. Aquí se repiten algunas de las profecías que aparecen en las obras anteriores, pero se intercalan disertaciones de cosmología y ciencias naturales, en las que se presenta al personaje como un sabio que vive solo en el bosque. El Merlín de la Vita Merlini tiene pues una imagen distinta del de la Historia. Se trata de un personaje más primitivo que conserva mucho de la tradición celta. No encontramos en este relato casi ningún elemento, salvo algunas menciones de Arturo, que tenga que ver con el ciclo artúrico. Quizá Geoffrey, debido al éxito de su obra anterior, decide escribir la Vita Merlini y darle un tono diferente al personaje, inspirándose en los poemas atribuidos a Myrddin o en la Vida de San Kentigern.

Aunque la Vita Merlini agrega nuevos detalles a la figura de Merlín, es la Historia Regum Britanniae la que fijará sus rasgos más significativos, que serán retomados por los autores franceses del siglo XIII, quienes conocieron el texto de Geoffrey gracias a la traducción realizada por Robert Wace en 1155, Le Roman de Brut. A partir de esta obra, se encargaron de dibujar una imagen muy completa de Merlín, quien se integró completamente al universo artúrico.

La obra de Robert de Boron fue determinante en la incorporación del mago a las aventuras de la Mesa Redonda. Inspirándose fundamentalmente 
en el Brut, el autor redacta a principios del siglo XIIl el primer ciclo artúrico francés dedicado a la historia del Grial, desde sus origenes, en la época bíblica, donde el Grial es identificado con el Cáliz de la Última Cena y en el que José de Arimatea recogió la sangre de Cristo tras su crucifixión, hasta la búsqueda de este objeto sagrado, en la época artúrica, por los caballeros de la Mesa Redonda. El ciclo está compuesto por tres partes: la Estoire del Saint Graal (Historia del Santo Grial), el Merlin y el Perceval. El Merlin, punto de transición entre la época bíblica y la de la caballería artúrica, fue concebido con el fin de preparar la aventura del Grial. Merlín ya no es aquí el profeta de la gloria y decadencia bretonas, como en la Historia Regum Britanniae, sino que se convierte en el profeta del Grial y de la cristiandad. Los orígenes del personaje se adaptarán entonces a esta nueva imagen religiosa. Su nacimiento es presentado aquí como el resultado de la decisión tomada en el Infierno, después de la Redención, de crear un ser, hijo de un demonio íncubo y de una doncella, dotado de poderes extraordinarios y destinado a engañar a los hombres y hacerlos caer en el pecado. Sin embargo, la maquinación diabólica fracasa debido a la gran fe de la madre de Merlín, quien es sólo una víctima del demonio. Así, al nacer, el niño es perdonado y recuperado por Dios, quien lo designa como su representante en la Tierra. Dotado de los poderes que los demonios le habían dado: inteligencia, memoria y conocimiento del pasado, así como del que Dios le concede: el conocimiento del porvenir, Merlín se convertirá en el instrumento divino destinado a una alta misión: anunciar y preparar el advenimiento del reino elegido para llevar a cabo la aventura del Santo Grial. El profeta se encargará de preparar los acontecimientos tal como Dios los ha planeado: la pacificación del reino bretón, el nacimiento y la elección de Arturo, y la creación de la Mesa Redon$\mathrm{da}$, institución predestinada al cumplimiento de la aventura del Grial.

El Merlin de Robert de Boron tuvo dos continuaciones que se encargaron de completar la biografía del profeta. La primera, denominada SuiteVulgate y redactada hacia 1235, fue incorporada al segundo ciclo artúrico francés, el Lancelot-Graal o ciclo de la Vulgate, realizado entre 1215 y 1230. La Suite-Vulgate relata los primeros años del reinado de Arturo y particularmente las innumerables campañas militares contra sus vasallos rebeldes. Como Paul Zumthor lo señaló, ${ }^{3}$ Merlín ya no es aquí el profeta del Grial, como en la novela de Robert de Boron, sino que se convierte en el profeta de las guerras de Arturo. En efecto, la función principal de nuestro personaje en esta novela es anunciar al rey los ataques del enemigo y asegurar la

${ }^{3}$ Paul ZUMTHoR, Merlin le prophète. Un thème de la littérature polémique, de l'historiographie et des romans, pp. 184-196. 
victoria utilizando sus poderes mágicos. Garantizar la pacificación del reino y consolidar la supremacía de Arturo son pues los principales objetivos de Merlín en la Suite-Vulgate. La alta misión del profeta, que en el Merlin era anunciar y preparar la aventura del Grial, queda aquí completamente olvidada.

En la Suite-Vulgate la historia de Merlín termina cuando éste sucumbe a los encantos de una joven llamada Viviana, a quien le transmite todos sus poderes a cambio de su amor. Una vez que la doncella se apodera de sus secretos, decide encerrarlo definitivamente en una prisión mágica de la que nunca más podrá salir. El profeta desaparece así del universo artúrico y es sustituido por Viviana, la Dama del Lago, quien se encargará desde entonces de proteger a los caballeros de la Mesa Redonda. La aventura amorosa de Merlín no sólo pone fin a su historia, sino que viene a completar las transformaciones del personaje.

La segunda continuación del Merlin de Robert de Boron, denominada Suite du Merlin, fue redactada hacia 1240. La novela parece haber formado parte de una nueva epopeya artúrica, conocida como ciclo Post-Vulgate, de la que sólo se conservan fragmentos. Como la Suite-Vulgate, la Suite du Merlin narra los sucesos acontecidos durante los primeros años del reinado de Arturo. Sin embargo, se trata de una versión totalmente distinta, dedicada ya no al relato de las campañas militares del rey, sino a preparar los grandes acontecimientos de la historia artúrica, narrados en las novelas que seguian a este texto dentro del ciclo Post-Vulgate: La Queste del Saint Graal (La demanda del Santo Grial) y La Mort le Roi Artu (La muerte del rey Arturo). El aspecto del profeta es retomado y ampliamente desarrollado en la Suite du Merlin. Sin embargo, adquiere un nuevo sentido. En efecto, ya no se trata aquí del profeta del Grial, del depositario de la palabra divina, imagen casi sagrada del personaje concebido por Robert de Boron, ni tampoco del profeta, consejero militar, de las guerras de Arturo, papel de Merlín en la Suite-Vulgate. De acuerdo con las intenciones de su obra, el autor de la Suite du Merlin, menos interesado en la imagen religiosa del personaje, vio esencialmente en éste un eficaz recurso narrativo para favorecer la cohesión de las distintas partes que conformaban el ciclo Post-Vulgate. Así, una de las principales funciones de Merlín en la Suite du Merlin es anunciar la aventura del Grial, narrada en la Queste, novela que venía después de la Suite $d u$ Merlin, y la muerte del rey Arturo, relato de la última parte del ciclo Post-Vulgate, La Mort le Roi Artu.

El autor de la Suite du Merlin retoma de la Suite-Vulgate el triste fin del profeta, traicionado por su amada Viviana. La versión que la Suite du Merlin ofrece de esta historia presenta algunas modificaciones, pero las líneas fun- 
damentales siguen siendo las mismas: cegado por el deseo, Merlín abandona su misión al lado de Arturo, alejándose del camino que Dios le había trazado, y es encerrado por la doncella en una prisión de la que ya no podrá salir. Así, el sabio, el gran profeta, será engañado por una mujer de la que se enamora y a la que revelará todos sus secretos. Este nuevo aspecto de Merlín rompe definitivamente con la imagen concebida por Robert de Boron. A través de esta fatal aventura, los continuadores del Merlin, los autores de la Suite-Vulgate y la Suite du Merlin, trataron probablemente de restablecer el origen diabólico del profeta, lo que al mismo tiempo les permitió deshacerse de un personaje que ya no tenía ningún papel en las siguientes partes del ciclo. Al arrancarlo de la influencia diabólica, Robert de Boron quiso convertir al hijo del demonio en símbolo de la gracia divina. Sin embargo, el espíritu mucho menos optimista que caracteriza a la Suite du Merlin será claramente puesto de manifiesto en esta nueva concepción negativa del personaje. Merlín cede a la tentación de la lujuria y es definitivamente abandonado por Dios y condenado a un encierro eterno. La Suite du Merlin marca el fin de la carrera del profeta en la literatura medieval francesa.

Dos siglos más tarde, cuando la leyenda de Merlín tiene ya cuatrocientos años de existencia, asistimos a la creación de un nuevo ciclo artúrico redactado en inglés por sir Thomas Malory, Le Morte Darthur (1485), que retoma la materia del Lancelot-Graal, del ciclo Post-Vulgate y del Tristan en prose. El relato dedicado a Merlín, titulado The Tale of King Arthur, es una adaptación libre de la Suite du Merlin. De esta manera, la obra de Malory, que se volvió un clásico de la literatura inglesa, vino a enriquecer la leyenda de Arturo y Merlín. Gracias a ella, la historia de nuestro personaje será ampliamente difundida en Gran Bretaña.

En el siglo XVI, Elis Gruffud escribe un texto en galés, Myrddin Wyllt, recuperando al Merlín primitivo de la Vita Merlini, al viejo profeta, al hombre silvestre. Algunas de las profecías que aparecen aquí son similares a las de la Historia Regum Britanniae.

Durante ese mismo siglo tenemos una obra más, un texto anónimo de 1532 que habla sobre Merlín y que, según Jean Markale, ${ }^{4}$ inspirará a Rabelais en la redacción de su Pantagruel. Aquí, Merlín será el creador de los padres de Gargantúa, quien irá a ayudar al rey Arturo a luchar contra sus enemigos. Así, gracias al ingenio de un autor del siglo XVI, el tema de Merlín se relacionará con el de Gargantúa.

El mago desaparece del mundo literario durante algún tiempo y sólo contamos con ciertas alusiones a él en varias obras: en el Orlando furioso de

${ }^{4}$ J. Markale, op. cit., pp. 36-37. 
Ariosto, Merlín revela a Bradamante las predicciones sobre los Estenses; en el Quijote es recordado como un gran mago y profeta, y en El rey Lear el bufón pronuncia frases jocosas referentes a nuestro personaje. Merlín no será verdaderamente recuperado sino hasta el siglo XIX, cuando un profundo entusiasmo por la Edad Media hará que artistas, escritores, críticos e historiadores vuelvan su mirada hacia el pasado lejano. Los textos medievales se recuperan y se empiezan a editar durante este siglo, y es así como la novela artúrica y, consecuentemente, la historia de Merlín despiertan nuevamente la curiosidad.

En 1860, Edgar Quinet publica Merlin l'Enchanteur, basándose en los principales elementos de la leyenda; Karl Immermann escribe un poema dramático titulado Merlin eine Mythe (1832); Tennyson, en sus Idyls of the King (1872), ofrece "Merlin and Vivien", retomando la historia de amor entre Merlín y la Dama del Lago. A finales del siglo XIX, Mark Twain escribe Un yanqui en la corte del rey Arturo, historia en la que un hombre de la época del autor transmigra, debido a un golpe, en cuerpo y alma al siglo VI, y se vuelve rival del mago.

Las diversas novelas de Merlín publicadas en nuestro siglo son una clara muestra de la pervivencia de esta gran figura legendaria. Sin embargo, el personaje ha sufrido muchos cambios, y las significaciones que puede tener en la literatura del siglo xx son evidentemente distintas de las que tuvo en la Edad Media. Tratar de recrear a un personaje como Merlín es una tarea que en algunas ocasiones puede dar resultados poco satisfactorios. Éste es quizá el caso de ciertas novelas del género de acción, suspenso y aventura, como la trilogía de Mary Stewart, The crystal cave (1970), The hollow hills (1973) y The last enchantment (1979), que trazan una silueta muy simple de nuestro personaje. Más interesantes nos parecen las recreaciones y las nuevas aportaciones de T. H. White, en su novela The book of Merlin (1958), y de John Steinbeck, en The acts of King Arthur and his noble knights (1976).

Dos novelas contemporáneas que vale la pena destacar por su calidad literaria son: el Merlin (1989) de Michel Rio, obra en la que nuestro personaje, a la edad de cien años, se convierte en el narrador de su propia historia, en el héroe principal del universo artúrico y en el único testigo sobreviviente de las aventuras de los caballeros de la Mesa Redonda y del trágico fin del reino de Logres. A través de Merlín, el autor manifiesta su concepción del hombre, de cualquier época, en su constante búsqueda de la verdad. Merlín es aquí el filósofo, en ocasiones pesimista y convencido de que los vicios humanos sólo llevan a la destrucción. Pero también es el sabio, el que puede probar a los demás que el verdadero poder está en el conocimiento y no en la fuerza. En este texto desaparece por completo la imagen del 
mago, aspecto que encontramos plenamente desarrollado en la novela de Barjavel, L'Enchanteur (1984), donde Merlín, mago y encantador, nos sorprende, quizá más que en ninguna otra obra de las que hemos mencionado, por lo maravilloso e ilimitado de sus poderes. Aquí, el autor convierte a Merlín en una figura alegre y llena de vida. El encantador se burla del tiempo permaneciendo siempre joven y apuesto para su amada Viviana, siempre activo y dispuesto a ayudar no sólo a los caballeros de la Mesa Redonda, sino a cualquiera que lo solicite. Sentado en la copa de su manzano, Merlín escucha pacientemente, comiendo una manzana mágica que nunca se acaba, las peticiones de la gente que hace una fila interminable para hablar con él, para hablar con el gran encantador que concederá sus deseos.

Merlín fue un personaje fundamental en la creación y desarrollo de la novela artúrica. Hijo del diablo, servidor de Dios, profeta, mago, organizador de la historia del rey Arturo y los caballeros de la Mesa Redonda, hombre cegado por la pasión, el personaje se identifica con todas y cada una de estas imágenes. De ahí su complejidad. Si lo analizamos desde el momento que se considera como el inicio de su desarrollo literario, con la obra de Geoffrey de Monmouth, hasta los últimos textos que aparecen en la Edad Media, podemos constatar cambios importantes: Merlín se irá transformando con los nuevos elementos que se van sumando poco a poco a su imagen. Si tratáramos de definirlo dentro de la novela artúrica francesa, el profeta sería el encargado de contar, anunciar, ordenar y construir la historia del pueblo elegido por Dios para el cumplimiento de la más alta aventura, la búsqueda del Grial. Todos los caballeros de la Mesa Redonda participarán en ella, pero sólo uno logrará llevarla a buen fin, Galaad, símbolo de perfección humana. La glorificación de la caballería como institución humana al servicio de Dios queda muy clara en la obra de Robert de Boron. Y es justamente Merlín el profeta, consejero y responsable de esta caballería celestial.

Inspirándose en la obra de Geoffrey, los autores franceses fueron construyendo poco a poco al personaje de acuerdo con las intenciones de cada texto. Merlín se adaptaba fácilmente a una obra de tono religioso, como la de Robert de Boron, pero había que caracterizarlo bien y dar una explicación de sus poderes sobrenaturales, enfocándolos dentro del marco cristiano. Sus múltiples facetas fueron surgiendo y transformándose. Así, del bardo y del profeta de la gloria bretona, pasamos al mensajero de Dios y luego al hombre enamorado que, cegado por los fantasmas del deseo, lanza su interminable grito de agonía desde algún lugar del bosque, donde fue encerrado.

Cada época tiene sus héroes míticos. A lo largo de la historia el hombre ha creado seres sobrenaturales que representan deseos, necesidades humanas o fuerzas de la naturaleza. Merlín obtiene, dentro de la novela artúrica, 
el privilegio de ser coautor, junto con Dios, de este universo. Pero los héroes duran sólo un tiempo; los hombres los crean y luego los destruyen para dar paso a nuevos modelos que satisfagan nuevas necesidades, que representen nuevos ideales. Sin embargo, Merlín no fue destruido; los mismos autores medievales que le dieron vida dejan que siga existiendo. Cuando el profeta queda encerrado en su prisión mágica o cuando decide voluntariamente ir a refugiarse al bosque, todo parece indicar que su gloria ha terminado, y en cierta medida es verdad, pues ya no volverá a aparecer en el universo artúrico. Pero Merlín no muere dentro de la literatura, pues será recuperado más tarde para seguir su trayectoria dentro o fuera de dicho universo.

\section{Bibliografía}

BARJAvel, René, L'Enchanteur. Paris, Gallimard, 1990 (folio, 1841).

GEOFFREY DE MONMOUTH, Historia Regum Britanniae, en La légende arthurienne. Etude et documentation, t. III. Ed. de E. FARAL. París, Champion, 1929.

Geoffrey de Monmouth, Vida de Merlin. Trad. de Lois Pérez CAstro. Prol. de Carlos Garcia Gual. Madrid, Siruela, 1986.

La Suite du Roman de Merlin. Ed. de Gilles RoussineaU. Ginebra, Droz, 1996. 2 vols.

L'Estoire de Merlin, en The Vulgate Version of the Arthurian Romances edited from Manuscipts in the British Museum. Ed. de Oskar SOMMER. 8 vols. Carnegie Institute of Washington, 1909-1913, t. II, 1908.

Les grands bardes gallois. Trad. de Jean MARKALE. París, Falaize, 1956.

Mabinogion. Ed. de Victoria CIRLOT. Madrid, Siruela, 1988.

MALORY, Thomas, sir, La muerte de Arturo. Trad. de Francisco TORRES OLIVIER. Madrid, Siruela, 1985. 3 vols.

MARKALE, Jean, Merlin l'enchanteur ou l'éternelle quête magique. París, Retz, 1984. 
MARX, Jean, La légende arthurienne et le Graal. París, Presses Universitaires de France, 1952.

Rı, Michel, Merlin. París, Seuil, 1989.

ROBERT DE BORON, Le Roman de l'Estoire dou Graal. Ed. de William A. NITZE. París, Champion, 1927; reimpr. 1983.

ROBERT DE BORON, Merlin, roman en prose du XIIIe siècle. Ed. de Alexandre Micha. París/Ginebra, Droz, 1980.

ZUMTHOR, Paul, Merlin le prophète. Un thème de la littérature polémique, de l'historiographie et des romans. Lausanne, Payot, 1943; 2a. ed., Ginebra, Slatkine, 1973. 